\title{
Lujo y devoción en el espacio residencial de doña Leonor Rodríguez de Fonseca y Toledo, Marquesa de Campotéjar (1605-1651)
}

\author{
JOSÉ ANTONIO GARCÍA LUJÁN \\ Universidad de Córdoba
}

Recibido: 26-04-2019

Aprobado: 05-07-2019

\section{RESUMEN}

A partir de fuentes notariales -cartas dotales, testamentos, codicilos, inventarios de bienes, tasación, adjudicación a herederos- se traza la biografía de doña Leonor Rodríguez de Fonseca y Toledo, marquesa de Campotéjar, así como el lujo y devoción que le acompañaron en vida. Lujo manifiesto por el mobiliario mueble, textil, plata y joyas de que disfrutó, y devoción por las pinturas religiosas, esculturas y oratorio privado que, además de ornar su residencia, muestran su indudable fervor sacro. Signos externos plenamente compatibles para dar a conocer la riqueza que se posee, expresar el rango elevado, refinado gusto y declaración inequívoca de piedad devota. Todo ello un buen ejemplo de otros muchos títulos de Castilla residentes en la Villa y Corte en pleno Siglo de Oro.

PALABRAS CLAVE: Lujo / devoción / biografía / bienes muebles / marquesado de Campotéjar, siglo XVII.

\section{ABSTRACT}

From notarial sources -dot cards, testaments, codicils, inventories of goods, valuation, award to heirs- the biography of doña Leonor Rodríguez de Fonseca y Toledo, Marquise de Campotéjar is traced, as well as the luxury and devotion who accompanied him during his lifetime. Luxury manifested by furniture, textiles, silver and jewelry that he enjoyed, and devotion to religious paintings, sculptures and private oratory that, in addition to adorning his residence, show his undoubted religious fervor. External signs fully compatible to make known the wealth that is possessed, express the high rank, refined taste and unequivocal declaration of devout piety. All this a good example of many other titles of Castilla residents in the Villa and Court in the middle of the Golden Age.

KEY WORDS: Luxury / devotion / biography / movable property / marquis of Campotéjar, XVII century. 
Es conocido el interés de la historiografía por los bienes suntuarios como exponentes de una clase social que los poseyó, acumuló y usó ${ }^{1}$; objetos que muestran ostensiblemente el alto rango de su propietario potenciándolo aún más con su exhibición ${ }^{2}$. Tal es el caso de doña Leonor Rodríguez de Fonseca y Toledo, marquesa de Campotéjar, que puede considerarse un buen ejemplo del lujo y devoción inherentes a numerosos nobles residentes en la Villa y Corte en la primera mitad del siglo XVII. Lujo, por los objetos de adorno personal y de los interiores de la residencia en que habita, y devoción, porque a través de muchos de ellos manifiesta su firme creencia religiosa dentro de los estrictos postulados de la Contrarreforma. Exteriorización de una pluralidad de elementos religiosos que en modo alguno son incompatibles con la exhibición de entes profanos de lujo, ya que unos y otros se complementan.

Fuentes fundamentales para este ensayo han sido el inventario notarial de bienes, tasación y adjudicación a herederos realizado en 1643 al fallecimiento de don Pedro de Granada Venegas Manrique, primer marqués de Campotéjar³, y así mismo la carta dotal, testamento, codicilos, inventario y tasación de los bienes de su consorte doña Leonor Rodríguez de Fonseca y Toledo al morir en $1651^{4}$. Como es común práctica notarial, las referencias son sucintas, y a veces incompletas, respecto a los bienes registrados y siempre concretas en cuanto a su valor de tasación al tratarse de un inventario judicial previo al reparto de legatarios; todas ellas, dispersas en un largo proceso que duró años, han sido sistematizadas en el análisis individual de los bienes ahora considerados.

\footnotetext{
1 T.VEBLEN, Teoría de la clase ociosa, Alianza Editorial, Madrid, 2014 [1899]; F. DAGOGNET, Éloge de l'objet. Pour une philosophie de la marchandise, Vrin, Paris, 1989; D. ROCHE, Histoire des choses banales. Naissance de la consommation, XVIIéme-XIXéme Siècle, Fayard, Paris 1997.

2 M. M. NICOLÁS MARTÍNEZ, «Lujo, ostentación y poder: a propósito de la casa marquesal de los Vélez», en Creación artística y mecenazgo en el desarrollo cultural del Mediterráneo en la Edad Moderna, R. CAMACHO MARTÍNEZ et al. (coord.), Universidad de Málaga, Málaga, 2011, pp. 65-92; C. HEREDIA MORENO, «El patrimonio suntuario de los V duques del Infantado»; M. M. NICOLÁS MARTÍNEZ, «Los legados de arte y objetos suntuarios de Mariana Engracia de Toledo y María de Aragón, marquesa de los Vélez, y sus inventarios de bienes (1686)», en Estudios de platería: San Eloy 2012, J. RIVAS CARMONA (coord.), Universidad de Murcia, Murcia, 2012, pp. 241-256 y 385-410; M. GARCÍA LUQUE, «Lujo, ostentación y poder: los palacios madrileño y lucentino de don Luis de Aragón, VII duque de Cardona, a través de sus inventarios», en Comercio y cultura en la Edad Moderna, J. J. IGLESIA RODRÍGUEZ et al. (eds.), Universidad de Sevilla, Sevilla, 2015, vol. 2, pp. 1331-1349.

AHPNM, protocolo 8213 .

AHPNM, protocolo 6253, fols. 397v-458r. 1651, noviembre 28. Madrid.
} 


\section{Biografía}

Escasas son las noticias biográficas; hija de don Alonso Rodríguez de Fonseca y doña Francisca de Leyva, señores de El Cubo (Salamanca), vinculados con la Casa de Alba, contrajo matrimonio, en 1605, con don Pedro de Granada Venegas Manrique de Mendoza $^{5}$, aportando como bienes dotales 85.895 reales/7.808 ducados en dinero, censos, joyas, ajuar y objetos de casa ${ }^{6}$. Concretamente, 22.000 reales de plata en dinero de contado; un censo de 12.000 reales de principal sobre el Estado del duque de Alba y renta de 722 anuales; un juro de 3.000 ducados de principal y rédito de 1.024 reales al año; sesenta botones de oro con tres perlas cada uno (5.000), un cinturón de oro "labrado a lo antiguo" con diamantes, perlas y rubíes (4.400), tres cadenitas de oro esmaltadas (2.200), dos sortijas de oro con un diamante (260), un Agnus Dei de oro (250); una escribanía de la India con cerradura y asas de plata, tintero y salvadera (150), un escritorio de Alemania (110), un contador pequeño de ébano y marfil (550); una porcelana de barro de la India con guarnición y asas de plata (22), una imagen de la Virgen (50); ajuar personal y de casa con sábanas de Rouen y colcha de Holanda (500) ${ }^{7}$.

En su matrimonio procreó a Alonso y Diego que murieron niños.

Vuelta la Corte a Madrid vivió hasta su muerte en la calle de Mediodía, casas lideras con la calle, las de don Francisco de Borja y Aragón, príncipe de Esquilache, y de don Ruy Gómez de Silva Mendoza, duque de Pastrana, que probablemente no desmerecerían a las de ambos admiradas por el cardenal Francesco Barberini en su visita en 1626 en la que estuvo presente don Pedro de Granada Venegas, mayordomo de la reina ${ }^{8}$.

\footnotetext{
Su biografía, exequias y notable biblioteca, una de las mejores de Madrid en la primera mitad del siglo XVII, en C. ÁlVAREZ MÁRQUEZ y J. A. GARCÍA LUJÁN, «Las lecturas de don Pedro de Granada Venegas, I marqués de Campotéjar (1559-1643)», Historia. Instituciones. Documentos, 35, 2008, pp. 149-189.

6 AHPNM, protocolo 8213, fol.10 y ss. 1605, septiembre 6. Valladolid. Al respecto, P. SÁNCHEZ-PARRA GARCÍA y C. CREMADES GRIÑÁN, «Los bienes de la mujer aportados al matrimonio. Evolución de la dote en la Edad Moderna», en Ordenamiento jurídico y realidad social de las mujeres: siglos XVI a XX, C. GARCÍA-NIETO PARÍS (coord.), Universidad Autónoma de Madrid, Madrid, 1986, pp. 137-148.

7 Ropa varia, basquiña, jubón, toallas, mantelerías, servilletas, almohadas, sábanas de criados y señores, estas labradas, dos cofres, baúl y calentador. Plata: bacinilla, jarrito, frasquito, cajita, aguamanil, destacando una salvilla de 284 reales.

8 C. DAL POZZO, El diario del viaje a España del cardenal Francesco Barberini; edición de Alessandra Anselmi, Doce Calles, Aranjuez, 2004, p. 246.
} 
Heredera universal, a partes iguales con la Obra Pía y Patronato instituido en su testamento por su marido, del gran patrimonio personal y de gananciales que dejó al morir ${ }^{9}$, integrado por activos financieros, bienes muebles e inmuebles urbanos y rústicos como cuerpo de hacienda previo al reparto de herederos ${ }^{10}$. Quedarse viuda no hubo de ser problema grave para doña Leonor, más bien no fue ningún problema con una herencia de treinta millones de maravedíes, que le permitiría no ya subsistir, sino vivir espléndidamente en el caso de que supiera y quisiera hacerlo así. No parece que como viuda llevase hábito a tenor del inventario de su vestuario personal, y con un patrimonio más que holgado estaba en una situación privilegiada con respecto a muchas de sus congéneres aristocráticas ${ }^{11}$, por lo que su vida de viuda pudo ser plena, o al menos muy placentera. Si lo fue o no, lodesconocemos.

Breve el testamento de doña Leonor: profesión de fe, inhumación en la parroquial de San Nicolás y posterior traslado de sus restos a la capilla del Sagrario en la catedral de Granada donde yacían su marido e hijos ${ }^{12}$, funeral moderado a juicio de los testamentarios, misa cantada de cuerpo presente con diacono, subdiácono, vigilias y novenario con misa cantada según costumbre, celebración de diez mil misas de alma por sí, padres y personas de su obligación, de ellas la cuarta funeral a la iglesia de la que era feligresa, las acostumbradas mandas forzosas en los testamentos por una sola vez y doce reales, y trescientos a los Santos Lugares de Jerusalem.

En él expresó, además de la dote matrimonial, pertenecerle la mitad de los bienes gananciales, debérsele 12.000 y 6.000 reales, se den 6.000 ducados a su sobrina Mayor de Fonseca y 2.000 a sus hermanas Francisca e Isabel para tomar estado. Legó a su sobrina Catalina Ronquillo 400 ducados de renta sobre los bienes confiscados en el reino de Granada, que incrementó en cuantía innominada en su segundo codicilo; una pintura de las mejores que poseía a las marquesas de Mancera, Ladrada y condesa

9 J. A. GARCÍA LUJÁN, «El alma única y universal heredera del patrimonio rústico de don Pedro de Granada Venegas Manrique de Mendoza, primer marqués de Campotéjar (1643)», Historia. Instituciones. Documentos, 44, 2017, pp. 131-150.

$10 \quad 29.529 .884$ maravedís a doña Leonor Rodríguez de Fonseca y 29.696.796 maravedís a la Obra pía, con un exceso de 166.912 maravedís que había de recibir aquella.

11 M. VIGIL, La vida de las mujeres en los siglos XVI y XVII, Siglo Veintiuno de España, Madrid, 1994, Capítulo «La viuda», pp. 195-207.

12 Así lo expresó también en un anterior codicilo de 17 de octubre de 1637. AHPNM, protocolo 5966, fols. 307r$308 \mathrm{v}$. 
de Baños en señal de afecto, parentesco y buena voluntad; libera a su esclavo Francisco de Espíritu Santo, da a sus criados diversas cantidades a juicio de los testamentarios y los lutos acostumbrados. Y del remanente que quedara de sus bienes instituyó por heredera a su alma "para que en beneficio de ella conviertan y distribuyan los testamentarios en las memorias y obras pías que quisieren y les parecieren"13.

Aún más concisos sus dos codicilos. En el primero, manda se cobren a su primo el duque de Alba 1.200 reales de los réditos de dos años de un censo, como alcaidesa del Generalife determina que los cuadros y retratos que había enviado para su adorno permanezcan en ese Real Sitio, y para el servicio de la capilla del Sagrario en la catedral de Granada, entierro y patronato de la Casa de Granada, un dosel, frontal, casulla y paño de terciopelo negro con las armas de su difunto marido ${ }^{14}$. Por el segundo codicilo reitera instituir a su alma como heredera universal de todos sus bienes ${ }^{15}$.

La residencia madrileña de los primeros marqueses de Campotéjar albergó abundante ajuar doméstico, rico y variado vestuario personal, armas, mobiliario suntuoso, valiosas tapicerías, numerosos objetos de plata, joyas de oro y diamantes, una buena biblioteca, un gran $\operatorname{archivo~}^{16}$, reliquias, esculturas religiosas, piezas curiosas y un centenar de cuadros de temática diversa, todo ello espejo perfecto para reflejar la dignidad de su alcurnia, siempre al servicio de la Corona, nobleza de origen regio nazarí y opulenta posición económica.

De entre toda esa riqueza que disfrutó, interesa ahora el espacio residencial cotidiano en que se desenvolvió su vida de lujo y devoción centrado en el análisis del mobiliario -escritorios y escaparates-, textiles -tapicerías, colgaduras, reposteros, doseles y alfombras-, plata labrada y joyas, oratorio privado para la práctica devocional, esculturas, pinturas y coches y silla de manos. Todo ello con el fin de lograr la habitabilidad necesaria, ornamentación adecuada y, sobre todo, representar a sus moradores y, en consecuencia, destacar su Casa, fidelidad católica y patrimonio.

\footnotetext{
AHPNM, protocolo 6252, fols. 657r-660v. 1651, octubre 31. Madrid. AHPNM, protocolo 4405, fols. 515r-517r. 1651, noviembre 19. Madrid. AHPNM, protocolo 6252, fols. 752r-753r. 1651, noviembre 20. Madrid.

J. A. GARCÍA LUJÁN, «La memoria escrita de la Casa de Granada: el archivo del marquesado de Campotéjar XV-1643)», Historia. Instituciones. Documentos, 40, 2013, pp. 35-79.
} 


\section{Mobiliario}

Con omisión consciente de los muebles de funcionalidad cotidiana, centro la atención en el mobiliario de lujo, a tenor de la estructura, maderas y ricos materiales -ébano, marfil, palosanto, nogal, concha de tortuga de carey, taracea, jaspe- y ornamentos que presenta -flores, animales en bronce-.

En efecto, en el moblaje de su vivienda los escritorios o contadores, de influencia flamenca y napolitana con amplia demanda en España y América en la décimo séptima centuria, pieza fundamental y muestra de lujo propia de las clases privilegiadas, están presentes en no corto número y varios de carácter arquitectónico: dos de cinco cuartas de largo y tres órdenes de alto cubiertos de ébano, 400 reales cada uno; uno largo de ébano y marfil con doce gavetas en un bufetillo de pino; dos iguales de vara de largo de palosanto, ébano y marfil, tres órdenes, enladrillados con florecillas de bronce y en las puertas dos águilas del mismo metal, sobre bufetes de nogal (400 unidad) ${ }^{17}$; uno cubierto de palosanto, marfil y nogal, cuatro órdenes (400); otro de palosanto, ébano y marfil de nueve gavetas; uno de vara y cuarta de largo, tres órdenes, perfilado de marfil cubierto de carey por delante (400); otro de concha de tortuga con adorno de ébano y marfil de doce gavetas más la puerta de en medio, sobre bufete de nogal, rematado en 330 reales; uno de tres cuartas, cubierto de ébano, tres órdenes, embutido de marfil (300); otro grande de taracea, ébano y marfil con ocho gavetas sin la puerta de en medio, de más de media vara de alto, sobre bufete de nogal.

De menor tamaño pero igual calidad, una escribanía de jaspe con cantoneras y aldabones dorados, tres escritoritos de Alemania, muy apreciados desde principios del siglo XVII por sus maderas claras con ricas incrustaciones de marquetería, uno de dos puertas y media vara de largo y una tercia de ancho con ocho gavetas, otro de una tercia de largo y una cuarta de largo, y un tercero de media vara de largo y una tercia de ancho ${ }^{18}$, una arquita de la India que servía de escribanía con cerradura, cantoneras, tintero y salvadera de plata $^{19}$, un escritorillo del Japón ${ }^{20}$, país del que también procedía un baúl de una vara de largo ${ }^{21}$, en tanto que otros tres estaban forrados con vaqueta de Moscú.

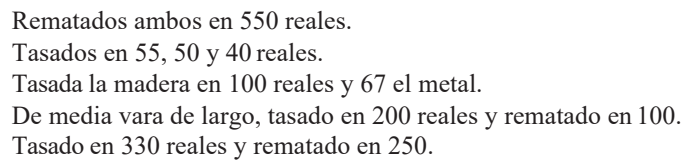


Y como casa rica, el restante mobiliario de madera comprendía escaparates de cedro ${ }^{22}$, bufetes, bufetillos - caoba, nogal, pino- taburetes de cañamazo de colores, sillas de terciopelo azul y carmesí bordadas o no, de vaqueta moscovita, arcones, cofres, arcas barreteadas o sin hierros, calentadores, escritorios papeleros, mesas grandes y pequeñas, escabeles, arquitas de nogal y cañamazo, espejo, mampara, arcas papeleras, estantes de libros, baúles de viaje, $\operatorname{camas}^{23}$, un catre de la India labrado con sus barandas ${ }^{24}$, toda una acumulación de bienes de uso ordinario para satisfacer las necesidades de la vida cotidiana y adornar la casa ${ }^{25}$.

A reseñar algunos objetos guardados en gavetas de los escritorios: dos cuchillos de Inglaterra, un manguito de piel de marta en caja de hojalata, seis jícaras de porcelana de Génova, tres ollas de Zaragoza, una pilita de agua bendita con la imagen de san José, el Niño y al pie santo Domingo guarnecida de vidrio; tres rosarios, uno de cocos negros de las Indias engarzados en cordón verde, otro de cuentas pardas engastado en acero y el tercero negro estriado encadenado en igual aleación, y dos libros de horas, en latín, unas con los cierres de plata y las otras de latón.

\section{Escaparates}

Piezas singularísimas por su número y calidad, algunos formando pareja, conteniendo todo tipo de piezas preciosas y exóticas de especial valor y calidad artística en tamaño reducido; signos externos para dar a conocer la riqueza que se posee, medio de ostentación propio de la época, expresión de elevado rango, gusto refinado y magnificencia en el ambiente doméstico, tres eran los escaparates ${ }^{26}$, repletos de cosas exquisitas, que embellecían el hogar de doña Leonor Rodríguez deFonseca.

Uno pequeño de caoba contenía, plata: un perfumador de faldas con mango y asas, dos ollitas con tapador, dos tembladerillas con asas, dos pomitos con tapador,

\footnotetext{
22 Dos rematados en 300 reales.

23 Además de las dos mencionadas posteriormente, una de pino pintada en negro, otra de beatilla con cinco cortinas, cielo y rodapiés tasada en 160 reales, y otra de viaje con los mismos textiles rematada en 400 reales con la madera.

24 Valorado en 100 reales.

25 Para el diverso mobiliario de esta época, M. P. AGUILÓ ALONSO, El mueble en España: siglos XVI-XVII, Consejo Superior de Investigaciones Científicas, Madrid, 1993.

26 Sobre este mueble, A. MORERAS VILLUENDA, El Escaparate, un mueble para una dinastía: ostentación y devoción en el Madrid de los siglos modernos, Tesis doctoral, UNED, Madrid, 2010.
} 
una campanilla, un bernegalillo, dos cajitas, una ruciadera, un cofrecillo estriado con tapador, dos vasitos a modo de jícaras, una cajita de plata dorada esmaltada de azul, dos ramilleteritos enrejados, tres salvillitas una redonda y dos largas con orejas de abanico, una salvillita blanca, una cajita estriada, dos pomillos estriados ${ }^{27}$, un salerito, un tenedorcito, dos salvilli- tas con sus vasitos, un vaso sobredorado por dentro y fuera; cristal: una tacita con el pie de oro, un aguamanil engastado en plata sobredorada, un pomillo de vidrio con tapador de plata; piedras raras: un ágata con pie y remate de plata sobredorada ${ }^{28}$, dos mariposas de piedra azul adornadas de plata.

En un segundo escaparate compañero del anterior, plata: dos pomos dorados, uno con dos óvalos y el otro estriado, un frasquito cerrado de plata sobredorada, tres pomitos, dos dorados y otro blanco; vidrio calado: seis escudillas, tres pocitos, un aguamanil; porcelana: ocho pocillos de porcelana fina, tres porcelanitas grandes, cinco platillos de porcelana fina, dos platillos de porcelana ordinaria; barros: seis, dos muy chiquitos y cuatro mayores de diferentes hechuras, una jicarilla de Valencia.

Y en un tercer escaparate de pino dado de negro y dorado situado en el estrado, y toda platería: cuatro tembladeras estriadas con asas, una olla grande con asas, una confitera con tapador y cuchara de nácar con mango de plata, una chocolatera, dos frascos medianos y dos pequeños con tapador, dos pomos pequeños con cuatro rosas grabadas y tapador, un cofrecito, un perfumador mediano con tapador, dos azafatillos de abanico, una salvilla estriada con óvalos y otras tres muy pequeñas, un bernegal aovado, una ollita, un vaso con tapador, seis jícaras, un cofrecito de carey con cerradura, pies y guarnición de plata.

Además de estos objetos, tienen particular interés el conjunto de cocos de las Maldivas que reunió doña Leonor; de singular aprecio en Europa y valor simbólico, sus presuntas cualidades preservativas o correctivas de los efectos del veneno, e imaginaria procedencia marina, los hicieron objetos de deseo convertidos en piezas

\footnotetext{
27 Valorados en 386,5 reales y rematados a la marquesa de Leiva en compensación de una pintura que le había legado en su testamento la marquesa de Campotéjar.

28 Tasada en 22 reales.
} 
de joyería, generalmente en forma de copa para beber ${ }^{29}$. Un total de once cocos, seis en uno de los escaparates y cinco en otro, de diferentes tamaños, con pie y guarnición plata todos menos dos, con tapador o no; tasación diversa: seis iguales, dos con tapador, todos guarnecidos de plata con sus pies y asas, 150 reales; tres diferentes con adornos de plata, 66; dos grandes engastados de plata con pies y asas grandes, $88^{30}$.

Netamente religioso es el así llamado Escaparate de las Muertes con veneración a reliquias y objetos sagrados, otro ejemplo más de serena convivencia de lujo y devoción que caracteriza al siglo XVII; exteriorización corporal de la fe, custodiadas en relicarios de alto valor y signo, a su vez, de prestigio, así como moda y declaración inequívoca de piedad religiosa y lealtad a la Iglesia. Un aspecto sin duda inquietante debía presentar este Escaparate de las Muertes, de pino dado en negro, forrado en terciopelo de igual color y aldabones plateados ${ }^{31}$, relicario integrado por un conjunto de objetos a los que doña Leonor debía atribuir algún tipo de fuerza sobrenatural de protección benefactora por su pertenencia o relación con personas o elementos sacros, transformando en joyas los recipientes que guardaban las reliquias.

En efecto, eran o debían ser de su particular devoción y aprecio setenta y ocho calaveras de cristal de diferentes tamaños con adornos de plata; ocho virilillos unos mayores que otros guarnecidos de plata con reliquias de santos; una caja de ébano y vidrio y en su interior un Cristo de marfil en el sepulcro tasado en 300 reales; una custodia de cristal con pie y engaste de plata; un gallo en oro de veintidós quilates en una columnita valorado en 391; una muerte y un vasito de $\operatorname{cristal}^{32}$, un sol, cuatro estrellas y cruz de plata, a los que acompañaban cuatro pebeteros, otros tantos candeleritos de triángulo y siete joyitas de plata, piezas todas tasadas en $1.932,5$ reales.

\footnotetext{
29 Análisis por N. VASSALO e SILVA, «Preciosidades e maravilhas entre Goa e Lisboa», en Exótica. Os Descobrimentos Portugueses e as Câmaras de Maravilhas do Renascimento, H. TRNEK y N. VASSALO e SILVA (eds.), Fundação Calouste Gulbenkian, Lisboa, 2001, pp. 27-37; L. CARVALHO y F.M. FERNANDES, «Exotica naturalia-O enigma do coco-do-mar», Artis, 9-10, 2010-2011, pp. 153-162; J. P.CABRAL, «La circulación de ideas, productos exóticos y joyería en Europa en los siglos XVI-XVII. El fabuloso coco de las Maldivas entre botánicos, comerciantes, joyeros y príncipes», Llul, 38, $2^{\circ}$ semestre 2015, pp.237-258.

$30 \quad$ Rematados estos dos a doña María Matienzo en 80 reales, y otros tres en 60 reales.

31 Su valor 110 reales, y 200 y 400 los otros tres escaparates.

32 Sobre el vidrio artístico, J. L. GONZALEZ GARCÍA, «El coleccionismo de vidrio artístico español en los siglos XVI y XVII», Boletín del Museo e Instituto Camón Aznar, 73, 1998, pp. 111-140.
} 


\section{Textiles}

Omnipresentes en las residencias de la nobleza y alto funcionariado ${ }^{33}$, no faltaban en la de doña Leonor Rodríguez de Fonseca. Así, para adornar las paredes y aminorar el frio invernal, una tapicería de cinco paños nuevos de la Historia de Abraham $^{34}$ aportada por don Pedro de Granada Venegas en su segundo matrimonio y vendida durante el mismo; tres paños de "figuras antiguas" sin precisar si temas de historia antigua o mitología, muy viejos y de poca calidad a tenor de su tasación ${ }^{35}, \mathrm{y}$ siete tapices ordinarios de la Historia de Moisés, sin más información, tema religioso predilecto de la nobleza desde mediados del siglo XVI. Mayor valor poseía una tapicería nueva, comprada matrimonio constante, de la Historia de Alejandro Magno en siete paños buenos ${ }^{36}$, embargada en 1643 por la Junta del Donativo y devuelta una vez cobrado ${ }^{37}$, y otra de siete paños de la Historia de Salomón ${ }^{38}$.

Colgaduras para ornamentar de mayor precio que los tapices. En concreto, una de terciopelo carmesí bordada con rasos de diferentes colores y perfiles de oro y brocateles de seda pajiza y encarnada con los flecos de oro y cenefas de brocatel con el mismo fleco 6.656 reales $^{39}$; otra de brocatel de oro y seda carmesí y dorado con sus goteras $(5.134)^{40}$; otra de terciopelo azul y damasco de dos colores $(2.432)^{41}$; una de brocateles dorado, carmesí y blanco con flecos con tres piezas de friso con goteras $(2.055)^{42}$; de tafetán encarnado y blanco (628).

\footnotetext{
33 J.FAYARD, Los miembros del Consejo de Castilla (1621-1746), Siglo XXI de España, Madrid, 1982.

De 4 anas de caída y un total de 105 anas a 6 reales ana, montan 630 reales en 1643.

Dos de ellos de 4 anas de caída, con 29 anas, tasada a 4 reales la ana, 116 reales, rematados en la almoneda a 3,5 ales la ana (101,5 reales).

36 De 5 anas y media de caída y un total de 209,5 anas.

37 Fueron varias las Juntas del Donativo que se constituyeron para el cobro de diversas donaciones que con carácter de voluntarias o repartidas se dieron en el reinado de Felipe IV; sobre ellas, J. F. BALTAR RODRÍGUEZ, Las Juntas de Gobierno en la Monarquía Hispánica (siglos XVI-XVII), Centro de Estudios Políticos y Constitucionales, Madrid, 1998, pp. 322-332

38 De cinco anas menos cuarta de caída ordinaria y maltratada, con 160 anas, tasada a 9 reales y rematada en la almoneda a 8 reales la ana (1.280 reales). Al respecto, M. T. CRUZ YÁBAR, La tapicería en Madrid, Instituto de Estudios Madrileños, Madrid, 1996; V. RAMÍREZ RUIZ, Las tapicerías en las colecciones de la nobleza española del siglo XVII, Tesis doctoral, Universidad Complutense de Madrid, 2012, https://eprints.ucm.es/16179/1/T33881.pdf.

39 Tasada la vara a 120 reales.

$40 \quad$ A 34 reales la vara.

41 Tasada a 16 reales la vara y rematada en 2 reales menos a la marquesa de Ladrada.

42 Tasada a 15 reales la vara y rematada en 1 real menos a la marquesa de Ladrada.
} 
Calidad textil que también se da en las camas, como una de palosanto y bronce dorado (1500 reales) con colgadura de gorgorán flor de romero con cinco cortinas, cielo, rodapiés y cobertor de lo mismo guarnecida con galón de seda (1.500), u otra de gasa forrada en tafetán con cinco cortinas, cielo, rodapiés, terliz de raso verde bordado con torzal de oro, cielo con goteras de oro, guarnecida con puntas de oro y el cielo con puntas mayores (2.750).

Símbolo de nobleza, reposteros y doseles mostrando las armas del linaje Granada, uso privativo del estado noble, y localización de honor en estancias bajo los que se sentaban los señores de la casa y recibían a los invitados: nueve reposteros nuevos de Salamanca ${ }^{43}$, un dosel de terciopelo azul con fleco de oro y seda y en medio las armas del marqués de Campotéjar bordadas de oro, y otro de damasco verde con cenefa de terciopelo de igual color dorado, 700 reales.

Labor de alto precio también presente en alfombras, como una decañamazo de seda de colores de ocho varas de largo por cinco y media de ancho 3.300 reales; de cañamazo azul, blanca, carmesí y otros colores de seda de cuatro varas y media de largo por tres y media de ancho ${ }^{44}$; de cañamazo de lana fina y diferentes colores de siete varas y media por cuatro y media ${ }^{45}$; de cañamazo bordada de seda y lana de diferentes colores con cenefa y flecos de oro de cinco varas de largo ${ }^{46}$; de lana blanca y negra ${ }^{47}$.

A buen seguro llamativa habría de ser la grande del estrado ${ }^{48}$ de viuda, aposento más característico de la vivienda, de siete varas y media de labores plateados y negros de lana; estrado con refinado aspecto luctuoso al estar amueblado con veinte almohadas de paño negro arriba y guadamecí abajo, paño bruno de ocho por cuatro varas con bocací negro, bufete cubierto de badana negra y sillas de terciopelo y vaqueta bruna $^{49}$, sala de cumplimiento y señal de luto constante que doña Leonor mantuvo de por vida una vez quedó viuda.

\footnotetext{
43 Adquiridos, 1643, en la almoneda de don Pedro de Granada Venegas en 110 reales cada uno por su primo don Pedro Francisco de Alarcón, que se los llevó y no pagó.

44 Rematada en 450 reales.

Tasada y rematada en 300 reales.

Tasada y rematada en 600 reales.

Rematada en 600 reales.

M.P.AGUILÓ ALONSO, Mueble español. Estrado y dormitorio, Consejería de Cultura, Madrid, 1990, pp. 106109.

49 Tasados en 440, 320, 250 y 20 reales respectivamente.
} 
De allende mares procedían una alfombra de la India ${ }^{50} \mathrm{y}$ otra de Turquía ${ }^{51}, \mathrm{y}$ producción nacional, un tapete de Alcaraz ${ }^{52}$. Otros textiles a reseñar: dos sobrepuertas y friso de brocatel con franja de oro; dos frontaleras bordadas sobre terciopelo verde; colcha de lino de Bujanda (Álava) labrada de cadenilla de tres varas de largo por ancho, 300 reales; servilletas y manteles alemaniscos, camisas, sábanas ${ }^{53}$ y colcha de Holanda ${ }^{54}$.

\section{Platay joyas}

La abundancia de plata americana conllevó la existencia de mobiliariovario en plata labrada, que se hallaba por doquier y bien a la vista de los visitantes; relación clara entre este metal noble y alta posición social, con valor funcional y monetario, numerosos eran los objetos de plata y muebles con adornos argénteos, no obstante las pragmáticas que prohibían los muebles de plata y limitaban el exceso de lujo y ostentación a la nobleza ${ }^{55}$.

La relación de los mismos constituye una larga lista de orfebrería doméstica integrada por cubertería, azafates, platos, fuentes, salvillas, ollas, jícaras, jicarillas, bernegales, velones, veladores ${ }^{56}$, candeleros de pie y de mesa, braseros, juncieras, jarros, escudillas, cazuelas, tembladeras, despabiladeras, ramilleteros, perfumadores, tijeras, copones, coponcillos, flamenquillas grandes y pequeñas, albahaqueros, pomos, pomitos, jarras, bacinillas, bujías, confiteras, chocolateras, bandejas grandes y

\footnotetext{
50 De algo menos de tres varas de largo y unas dos de ancho, tasada en 50 reales y rematada en 40.

51 De vara en cuadro, valorada en 12 reales.

52 De tres varas de largo por dos de ancho, vieja y rota, 40 reales. Sobre esta localidad famosa por su fabricación de alfombras y tapetes, J. SÁNCHEZ FERRER, Alfombras antiguas de la provincia de Albacete, Instituto de Estudios Albacetenses, Albacete, 1986.

53 Tasadas en 60 reales la unidad y rematadas en 52

54 De 4 varas de largo, 600 reales y rematada en 220. De propósito se excluye el análisis de la ropa personal, blanca y de servicio notable por su cantidad y calidad.

55 J. SEMPERE GUARINOS, Historia del Luxo y de las leyes suntuarias de España, Imprenta Real, Madrid, 1788; M. C. HEREDIA MORENO y A. LÓPEZ-YARTO ELIZALDE, La edad de oro de la platería complutense (1500-1650), Consejo Superior de Investigaciones Científicas, Madrid, 2001; S. MARTÍNEZ BERMEJO, «Beyond Luxury: Sumptuary Legislation in 17th Century Castile», en Making, using and resisting the law in European history, edited by G. LOTTES et al., Plus-Pisa university press, 2008, pp. 93-108; J. PORTÚS PÉREZ, «Belleza, riqueza, ostentación. Significados y metáforas de la plata en el Siglo de Oro»; M. C. HEREDIA MORENO, «Lujo y refinamiento. La platería civil y corporativa», en $E l$ fulgor de la plata, R. SÁNCHEZ-LAFUENTE GEMAR (coord.), Consejería de Cultura. Junta de Andalucía, Córdoba, 2007, pp. 26-41 y 66-83.

56 A cambio de una alhaja que legó a doña Mariana de Zúñiga, se le dio un velador de plata que pesaba 1.401 reales $(4,69 \mathrm{~kg}$. 1 real $=3,35$ gr. $)$ y tasada su hechura en 330 reales.
} 
pequeñas, cofrecitos. Piezas destacables de valor superior a 500 reales: dos pomos grandes para agua de olor (523), dos platos gallineros (538), veinte platos trincheros (2.409), un set de salero, pimentero, azucarero, vinagrera y aceitera con un rinoceronte de bronce encima (709,5), dos juncieras (735), un velón (598), brasero (1.384), velador (1.401), y para mitigar la sed en los viajes un cubo y cantimplora ${ }^{57}$.

Así mismo, objetos de plata mostrando las armas del marquesado de Campotéjar: una olla con pico y asa, platos grandes y medianos, dos fuentecillas, plato grande redondo con molduras (662), dos frascos chatos con tapaderas y cadenas (1.246), un braserito de mesa, dos frascos grandes, despabiladeras ${ }^{58}$. Y en plata sobredorada: azucareros, pimenteros, vinagreras, salseras, salvillas, bernegales, tazas, vasos, jarros, ramilleteros y una salvilla grande con relieve dorado de un caballero en medio armado sobre un caballo ${ }^{59}$.

Las joyas, ausentes en muchos de los inventarios post mortem, están presentes en el de la primera marquesa de Campotéjar, bienes libres no sometidos a vínculo; notable acumulación de capital, guardadas en cofres y arquitas, doña Leonor poseyó un respetable conjunto de joyas acorde con su estatus nobiliario, esposa de un mayordomo de la reina Isabel de Borbón y miembro de la Real Junta del Bureo, para lucimiento y adorno personal en los actos palatinos que así lo requerían y visibilidad de su nobleza y poder.

A las aportadas en la dote valoradas en 11.900 reales, se sumaron al morir alhajas todas de oro y brillantes tasadas en 14.079 reales: cosidos para embellecer el vestuario, ciento treinta y cuatro botones grandes de oro, calados y tirados $(2.810)^{60}$, y cuarenta y dos estriados y huecos $(1.305)^{61}$. Y para arreglo propio, una cadena de cuarenta y tres eslabones esmaltados de colores con un diamante cada uno (3.476), otra cadena gruesa

\footnotetext{
57 Con dos asas y el pie con tapador y cadena, peso de 23 marcos y 5 onzas, tasados y rematados en 1.535 reales.

58 Objetos no siendo de plata que llevaban el escudo de armas: platos gallineros, medianos y pequeños, flamenquillas, fuentes, salvillas, jarros.

59 Rematada en 208 reales y 24 la hechura.

60 Con un peso de 140 castellanos y 4 tomines (646,39 gramos) y oro de 22 quilates, rematados en 2.714 reales

61 Con un peso de 65 castellanos y 2 tomines $(300,19$ gramos) y oro de 22 quilates, rematados en 1.260 reales. Sobre estas técnicas de orfebrería del oro, A. CARBONEL, Encyclopedia metódica. Fábricas, artes y oficios, Imprenta de Sancha, Madrid, 1794, pp. 417-419.
} 
$(1.180)^{62}$, un cordón largo, hechura de Portugal, $(710)^{63}$; unas arracadas de medias lunas y treinta y cuatro diamantes (528), unos brazaletes con esmaltes de colores con diez piezas, cinco con tres diamantes y las otras cinco con uno -40 diamantes las dos manillas- (902) sin la hechura, y un broche esmaltado con doce diamantes (429). Sortijas: con dieciocho diamantes (704), con cinco diamantes (506), con quince diamantes (363) y pequeña con once diamantes ${ }^{64}$. Considerada como joya, una imagen de la Virgen en una cajita de plata labrada y oro con el Santísimo y dos santos en las cubiertas ${ }^{65}$.

\section{Oratorio}

Espacio particularmente asociado a la mujer, expresión de devoción y sentimiento religioso ${ }^{66}$ y representación de la suntuosidad de una casa y de quienes la habitaban, el oratorio no faltaba en la residencia de doña Leonor, prototipo rotundo de acumulación de riqueza consustancial a la nobleza madrileña en el siglo XVII, del que puede considerar un buen ejemplo el de la marquesa de Campotéjar.

Amplio, rico y refinado oratorio privado a tenor de la cantidad y calidad de objetos que albergaba. En el altar, con piedra de ara, cubierto de corporales con puntas forrados de tafetán carmesí, presidido por una imagen grande de la Encarnación, hostiario de carey, misal, cáliz con patena de plata sobredorada, atril, salvilla y vinagreras, calderita de agua bendita ${ }^{67}$ y dos candeleros altos todo de plata, campanilla de metal, una tabla con las palabras de la Consagración, otra del evangelio de san Juan, y Cristo en una cruz pequeña de ébano y peana de plata.

Para revestimiento del oficiante en los diversos tiempos litúrgicos, dos albas de Holanda con sus puntas, amitos y cíngulos, una casulla de tafetán doble morado con galón de oro, estola, manípulo, frontal y bolsa de corporales de igual tejido; otra casulla de tafetán doble verde con galón de oro, estola, manípulo, bolsa de corporales

\footnotetext{
62 Con un peso de 59 castellanos (271,4 gramos) y oro de 22 quilates. Rematada en la almoneda en 1.166 reales

63 Con un peso de 35 castellanos y 4 tomines (163,39 gramos) y oro de 22 quilates, rematado en la misma cantidad de tasación.

64 Sin tasar.

65 Rematada en 10 reales.

66 L. MALO BARRANCO, «Los espacios de religiosidad y la devoción femenina en la nobleza moderna. El

ejemplo de los linajes Aranda e Híjar», Cuadernos de historia moderna, 42, 2017, pp. 175-193.

67 Rematada en 176,5 reales.
} 
y frontal con cenefas de red forrada en velillo de plata y gradas del mismo tafetán;y una tercera casulla de tafetán blanco doble con pasamano de oro, estola, manípulo, frontal de raso blanco, bordado con el escudo de armas del marquesado Campotéjar, gradas del mismo raso y bolsa de corporales de tafetán blanco.

Sin precisar localización, dos retablos pequeños de pasta verde y guarnición de ébano, y relicarios: dos pequeños de santa Teresa de Jesús, dos guarnecidos de ébano, otros tantos de ébano y bronce, ocho pirámides de diferentes tamaños con pies y remates de plata, y un Agnus Dei con reliquias dentro de una cajita de madera dorada con dos puertas y bisel esmaltado de colores $^{68}$.

Esculturas de bulto redondo, la Virgen de la Concepción con corona de plata y peana dorada, tasada en 700 reales, Virgen con el Niño en brazos de alabastro (200), san José vestido con tela de oro y negro con su vara en la mano (150) y un Niño Jesús dormido en una camita con su colgadura en tafetán azul (300) y otro de bulto vestido (330). De medio cuerpo, un Ecce Homo en pasta con barandillas, trono de madera y arco con rayos todo dorado (600), y dos santos obispos de cartón en sus peanas (16).

Un conjunto de quince cuadros. En tabla, pequeño tamaño, Desposorio de santa Catalina con marco dorado y negro, san Francisco con las llagas en las manos, de medio cuerpo, moldura de peral negro, y la Anunciación. En lienzo, probablemente, santa Matilde de medio cuerpo sin marco, con marcos dorados y negros san Onofre (20 reales), santa Gertrudis, san Ildefonso (20), Niño Jesús, uno pequeño del Descendimiento de la Cruz (440), otro mediano de vara y cuarta con san Pedro y el gallo (50), otro grande de La Anunciación, y una lámina ${ }^{69}$ de la Virgen de la Leche con moldura dorada. Junto a ellos, los retratos de fray Luis de Granada, fray Juan de Granada y fray Leandro de Granada Venegas, hermano del marqués de Campotéjar, estudiante de Teología en Alcalá de Henares, tomó el hábito de san Benito en Salamanca en cuya Universidad fue maestro en esa ciencia, y definidor general de su Orden; primer traductor al español y divulgador de la visionaria San-

\footnotetext{
68 Con un peso de 3 castellanos y 2 tomines (14,99 gramos) y oro de 22 quilates, tasado en 65 reales. 
ta Gertrudis la Magna ${ }^{70}$, a su pluma se deben diversas obras de carácter ascético y místico $^{71}$.

Y para completar el adorno e iluminación del oratorio, cuatro ramilleteros de plata con veinte flores de mano grandes y pequeñas, otros seis de madera colorados y dorados ${ }^{72}$, dos angelitos de bulto en peanas doradas que servían de candeleros 200 reales, cuatro candeleros de plata, tres pequeños, dos de vidrio y bronce (120), dos arañas de plata de tres mecheros cada una, y un perfumador de plata.

Cubriendo el sitial, desde el que asistían a los actos litúrgicos los marqueses de Campotéjar, un dosel de tafetán carmesí con flecos.

Otras esculturas de bulto redondo sobre peanas doradas, fuera del oratorio, distribuidas en diversas estancias con una doble finalidad religiosa y decorativa, un Niño Jesús con corona de plata vestido de lama de flores, gasa y camisa blanca con puntas y cadena de azófar dorada, 330 reales, san Antonio con el Niño Jesús en el brazo (600), santa Teresa con una paloma junto a la cabeza (605), y un pequeño san Juan con el Cordero en la mano (300).

\section{Pinturas}

Junto con tapices, colgaduras y reposteros que cubrían las paredes, e incrementando aún más el ornato, pinturas repartidas por las diversas salas, excluidas las del oratorio ya mencionadas y las de la galería de retratos, cuyo estudio se omite ahora por requerir un análisis particular que supera los límites fijados por el editor. Necesariamente hay que distinguir entre las pertenecientes a don Pedro de Granada Venegas por ser bienes privativos, y las que eran propiedad de doña Leonor Rodrí-

70 L. C. ÁLVAREZ SANTALÓ, «Fray Leandro de Granada. Divulgación científica de las técnicas visionarias. El imaginario religioso a las aulas lógicas», en Iglesia y Sociedad en el Reino de Granada (ss. XVI-XVIII), A.L. CORTÉS PEÑA et al. (eds.), Universidad de Granada, Granada, 2003, pp. 265-310.

71 Luz de las marauillas que Dios ha obrado desde el principio del mundo en las almas de sus Profetas ... Valladolid, 1607; Admirables y regaladas reuelaciones ... Valladolid, 1607; Libro intitulado Insinuación de la diuina piedad reuelado a Santa Gertrudis. Traduzido de latín en romance por ..., al qual de nuevo intitula Pratica de perfección y añade vnos discursos, y vnas scolias al fin de cada capitulo ... primera parte, Madrid, 1614; Segunda y vltima parte de las admirables y regaladas Reuelaciones de la gloriosa S. Certrudis, Madrid,1614.

72 Dos de ellos 44 reales, y los otros cuatro 32 reales. 
guez de Fonseca, incrementadas con aquellas al heredarlas al quedar viuda en 1643.

Exigua presencia de la mitología con una sola obra, Cupido en un lienzo de dos varas de alto y marco dorado y negro, tasado en 300 reales al morir don Pedro de Granada, retasado en 200 en el cuerpo de hacienda y adjudicado a la hijuela de doña Leonor, a cuya muerte fue tasado en 300 reales.

El género pictórico del bodegón, de gran éxito en la España del Siglo de Oro $^{73}$ presente en numerosas casas, lo estaba en la de doña Leonor con un par de lienzos pequeños sin marco mostrando dos fruteros.

Mayor número en cuanto a la plástica naturalista centrada en escenas de paisaje, tipo generalizado a partir del segundo tercio del siglo XVII, destacando tres lienzos grandes - "retratos"- de las villas de Campotéjar, Jayena y la Casa Real del Generalife, señorío jurisdiccional ambas y alcaidía el Real Sitio de don Pedro de Granada Venegas primero y de doña Leonor después de fallecer. Tasados los dos primeros en 110 reales y retasados en 150 fueron adjudicados a la Obra Pía y Patronato instituida como heredera por don Pedro de Granada, junto con el del Generalife valorado en 66 reales y revalorado en 44; sin embargo, este lienzo y el de Jayena, sin marcos, quedaron en poder de doña Leonor y tasados uno y otro al morir en 55 reales.

A ellos hay que sumar un "retrato de la Habana", esto es, una vista en lienzo sin marco valorada en 22 reales y adjudicada a la hijuela de doña Leonor, y otra del castillo de Madrid con marco dorado y negro de la que era propietaria y tasada en 66 reales a su fallecimiento.

De un conjunto de seis países, tres al temple, viejos, valuados en 24 realesy vendidos por el mismo precio en la almoneda de don Pedro de Granada, en tanto que dos pequeños, viejos, con marcos dorados, y otro con una cenefa de flores tasadoen 30 reales y retasado en 22, fueron asignados a la hijuela de la marquesa de Campotéjar. Asimismo, con valor de 22 reales y retasados en 16 cuatro "retratos" pequeños,

3 P.CHERRY, Arte y naturaleza. El bodegón español en el Siglo de Oro, Fundación de Apoyo a la Historia del Arte Hispánico, Madrid, 1999. 
lienzos al temple, de los cuatro continentes, e igualmente las estaciones del año, -"los quatro elementos" o "los quatro tiempos del año"-, lienzos de tamaño mediano, marcos negros y dorados en las esquinas, tasados cada uno en 110 reales, retasados en 80 y rebajados a 66 al morir doña Leonor. Esta era dueña de tres países, grandes, con unas casas, barcas y aguas y valor de 55 reales unidad, dos pequeños viejos con marcos dorados y de un Mapamundi grande con marco, en papel, justipreciado en 100 reales.

De tema indefinido es "una tabla a tres aces/quadro que hace tres caras/ pintura que hace tres caras"; ¿podría referirse a un tipo de retrato, nada frecuente, en el que, valiéndose de espejos, se muestran tres visiones del rostro simultáneamente?; ¿o quizás una representación trifronte? ${ }^{74}$; heredada por doña Leonor Rodríguez de Fonseca, su bajo valor de 20 reales no parece avalar una de esas dos posibilidades.

Pero el género que tiene más peso es el religioso con presencia mayoritaria de escenas del Antiguo y Nuevo Testamento. En efecto, eran propiedad de don Pedro de Granada Venegas una tabla pequeña de la Creación del Mundo, marco sobredorado, tasada en 300 reales y retasada en 150, un "retrato" de Lot, lienzo sin marco en 66 y 44 reales, una Santa Cena de tres varas de alto por dos de ancho con marco negro y valorada en 660 reales, y una Magdalena muerta, de vara y media de alto y una y cuarta de ancho, marco negro, en 40 reales, pinturas atribuidas a la marquesa de Campotéjar en su hijuela, a cuya muerte fueron retasadas las tres últimas en 40, 550 y 100 reales respectivamente. Un martirio con unas cabezas cortadas, lienzo tasado en 66 reales y retasado en 44, fue adjudicado a la hijuela de la Obra Pía y Patronato.

Por su parte doña Leonor era dueña de cinco cuadros todos del mismo tamaño y marco que el precitado de la Santa Cena -tres varas de alto por dos de ancho-, mostrando el Nacimiento de Jesús, la Adoración de los Reyes, Presentación de Jesús en el templo, la Oración en el Huerto y Cristo con la Cruz y la Verónica, con un valor de tasación de 700 reales unidad, excepto la Oración en Getsemaní (550).

A estas pinturas acompañaban, como mediadora en el Cielo, objeto de devoción y protección frente a la enfermedad e infortunio, una pequeña Soledad con

74 Agradezco a Miguel Ángel León Coloma la información respecto a esta tabla de impreciso tema. 
las insignias de la Pasión, una Dolorosa con Cristo muerto en sus brazos al pie de la Cruz y marcos negros, una Verónica y un san Jerónimo ambos de vara de alto y tres cuartas de ancho sin marcos, y una lámina de Nuestra Señora del Pópulo con Jesús en brazos y marco de ébano.

Excepcionalmente a solo tres pinturas se asigna artista: Jerónimo el Bosco, autor de dos "cuadro país" con las Tentaciones de san Antón abad, en tabla, pequeño formato y marcos dorados, uno vendido en la almoneda de don Pedro de Granada al rematarse por 120 reales a don Juan Ramiro de Liébana Quiñones, y el otro, muy maltratado, junto con una tercera tabla de igual tamaño y marco representando a San Cristóbal, heredadas ambas por doña Leonor; tasada y retasada la primera en $300 \mathrm{y}$ 150 reales, y en otros 300 la que efigiaba al portador de Cristo, cuyos valores seminoraron a 50 y 110 reales respectivamente cuando esta murió.

\section{Coches y silla de manos}

Signos visibles de prestigio y diferencia social a la par que demostración del poder económico y lujo de un linaje noble ${ }^{75}$. En un tiempo en que son numerosas las pragmáticas contra el exceso en el uso de estos bienes, doña Leonor tuvo para su disfrute dos coches, uno de baqueta ordinaria con las cortinas de paño colorado y almohadas negras, y otro grande verde con cortinas de damasco y almohadas de terciopelo del mismo color, cortinas y estribos de invierno; en tanto que los animales para su tiro eran engalanados con petral de cascabeles de bronce, caparazón turco pespunteado con seda de colores y, de plata, jaez, petrales, cuerda, cabezada, ahogador, acicates y estribos chapados en el mismo metal, todo ello guardado en bolsas de seda morada, oro y plata con valor de tasación 550 reales. ${ }^{76}$ Para distancias cortas dispuso de una silla de manos negra de vaqueta forrada en damasco del mismocolor ${ }^{77}$.

\footnotetext{
75 Su análisis por A. LÓPEZ ALVAREZ, Poder, lujo y conflicto: coches, carrozas y sillas de manos en la Corte de los Austrias, 1550-1700, Polifemo, Madrid,2007.

76 Vendido en la almoneda por 1.150 reales.

77 Rematada en la marquesa de Ladrada en 435 reales.
} 


\section{A modo de conclusión}

En páginas anteriores se ha analizado el conjunto de objetos suntuarios existentes en la residencia madrileña de doña Leonor Rodríguez de Fonseca y Toledo, marquesa de Campotéjar, a través de cuya posesión y ostentación resalta aún más su imagen, posición social, prestigio, refinamiento, opulencia y poder ante propios y extraños, hecho característico de la nobleza en la primera mitad del siglo XVII. Bienes patrimoniales profanos y sacros que muestran la armónica compatibilidad entre lujo y devoción, riqueza en la vida terrenal y fervor religioso en la espiritual.

Numerosas preguntas se plantean. ¿Quiénes fueron los autores de estos bienes de lujo?. ¿Cuál era la calidad de estas obras de arte a tenor de su valor de tasación y quiénes los artistas que las crearon?. ¿Se trata de lienzos y tablas originales o copias, o más bien unos y otras?. ¿Cabe pensar en alguna voluntad de cohesión temática de las pinturas?. ¿Tenía doña Leonor algún interés por el arte y conocimiento al ser la propietaria del conjunto de cuadros de mayor precio?. ¿La compra responde a su gusto artístico y a una incipiente voluntad de coleccionista?. ¿Los adquirió por su propio deseo y sensibilidad, o influenciada por los de su consorte?. ¿La meditación sobre la muerte fue elemento cotidiano en su vida? ¿Tenía algún límite su amor por el lujoy la devoción?.

La respuesta a estas interrogantes solo será posible cuando se acceda y estudien los ricos fondos del archivo del marquesado de Campotéjar, inventariado en 1643 y conservado inédito hasta nuestros días. 